\title{
Numerical modeling of wind waves affected the marine structures in the Kola Bay
}

\author{
Izmail Kantarzhi* and Aleksandr Anshakov \\ Moscow State University of Civil Engineering, Yaroslavskoe shosse, 26, Moscow, 129337, Russia
}

\begin{abstract}
In this study of the evaluation of wave impacts on a gravity base structure (GBS) which is moored to berth No. 5 of the Centre of construction of large-capacity marine structures (CCLMS). It was identified five main wind directions that can be dangerous for the construction of CCLMS: East direction (E) South-East (SE) South direction (S), Southwest (SW), West (W) and Northwest (NW). According to the results of statistical processing of extreme storms of the 30-year period, two most dangerous directions of unrest were chosen-the Eastern direction (B) and the South-Eastern (SE) direction. Using a numerical model ARTEMIS, it was received wave field in the waters CCLMS near GBS reading for different sea levels. The simulation results showed that the wave heights affected the structure can reach $2.4 \mathrm{~m}$.
\end{abstract}

\section{Introduction}

The center for the construction of large-capacity marine structures (CCLMS) is planned to be built in the area of Belokamenka village on the Northern shore of the middle knee of the Kola Bay between the Belokamenka and the Bolshoi capes. This plant in the dry docks will build a concrete gravity base structures (GBS). The production of high-tech modules "turnkey" will be deployed in the workshop of the complex for the production of the upper structures-from cutting to the final assembly of modules in a huge assembly shop. Readymade modules on self-propelled trolleys will be transported to dry docks, where modules will be transferred to GBS with subsequent integration into a single line of the gas liquefaction process (Fig. 1).

In this study, a simulation of a wave situation, when terminal No. 5 CCLMS moored by gravity base structure (GBS).

\section{Set-up of the models}

It is known that in the waters of the Kola Bay may excitement due to penetration into the bay of waves coming from the Kara sea, and wind waves of the local acceleration.

The analysis of wind waves for the 30-year period 1987-2016 showed that the waves of the open sea in the middle knee of the Bay penetrate significantly weakened and they are much lower than the waves of local acceleration.

\footnotetext{
*Corresponding author: kantardgi@yandex.ru
} 
Local wind waves, was allocated to five main directions that can be hazardous to structures CCLMS not protected with a protective moles are East direction (E) South-East (SE) South direction (S), Southwest (SW), West (W), and Northwest (NW).

To calculate the elements of waves of different frequency of the 30-year period were selected maximum storms for the year, 30 storms for each direction. For each storm, wave fields in the middle knee of the Kola Bay were calculated using the spectral wave model SWAN [1,2]. Further, with the help of Weibull distributions, the wave elements of different repeatability and security in the control points on the approach to the port facilities were calculated.

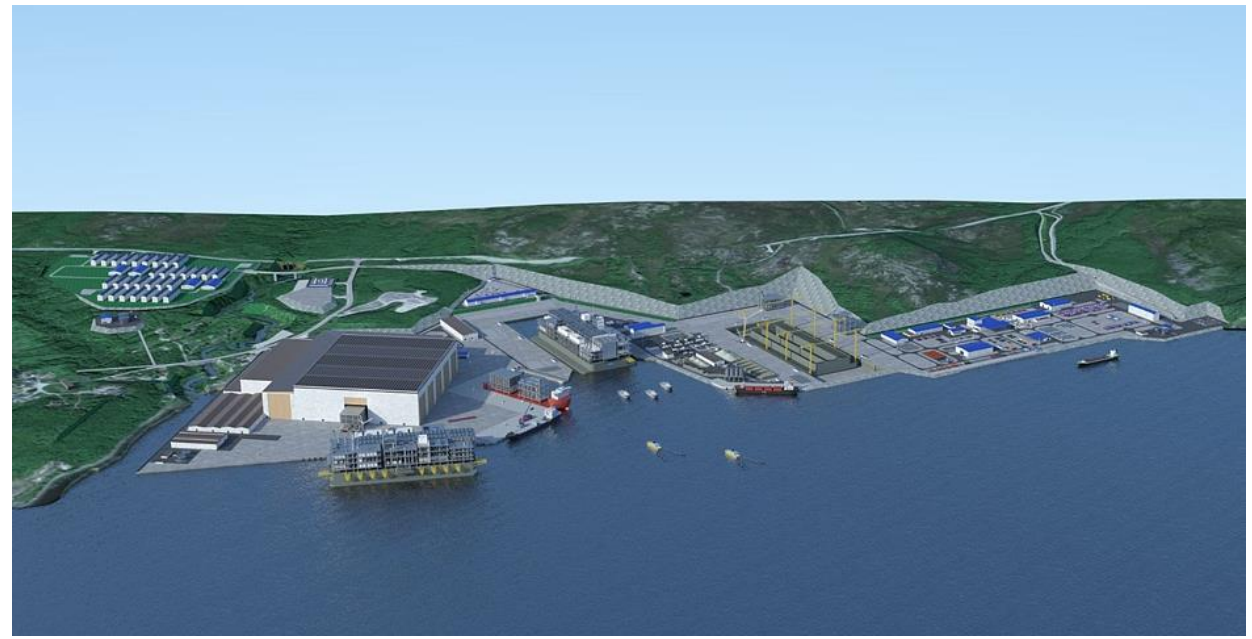

Fig.1.The layout of the project CCLMS

The wave parameters at the control points were used to initialize the refractivediffraction model based on the equations of gentle slopes (MSE) ARTEMIS [3], which calculated the wave elements of different repeatability in the water area of the object and near the berths.

To assess the wave effect, waves of $\mathrm{E}$ and SE directions were modeled with repeatability of 1 time per 50 years, $5 \%, 1 \%$ and $0.1 \%$ accedances, near the GBS moored to the berth No.5.

To solve this problem, the wave model ARTEMIS, open source code, which is part of the TELEMAC software system [4], was chosen. The model solves the MSE using the finite element method on an unstructured computational grid with triangular elements. It describes the reflection of waves from obstacles, the diffraction of waves behind obstacles, the refraction of waves on the inhomogeneities of the bottom, bottom friction and the breaking of waves. While it allows you to enter different coefficients of reflection of the waves in the border areas of the computational domain, and appropriate port facilities of different types: vertical piers, with the piers of the trestle type, a variety of slopes with different slope and dumping. The final bathymetry of the middle knee of Kola Bay in the area of CCLMS, from the Great Cape to Cape Contadina shown in Fig. 2. 


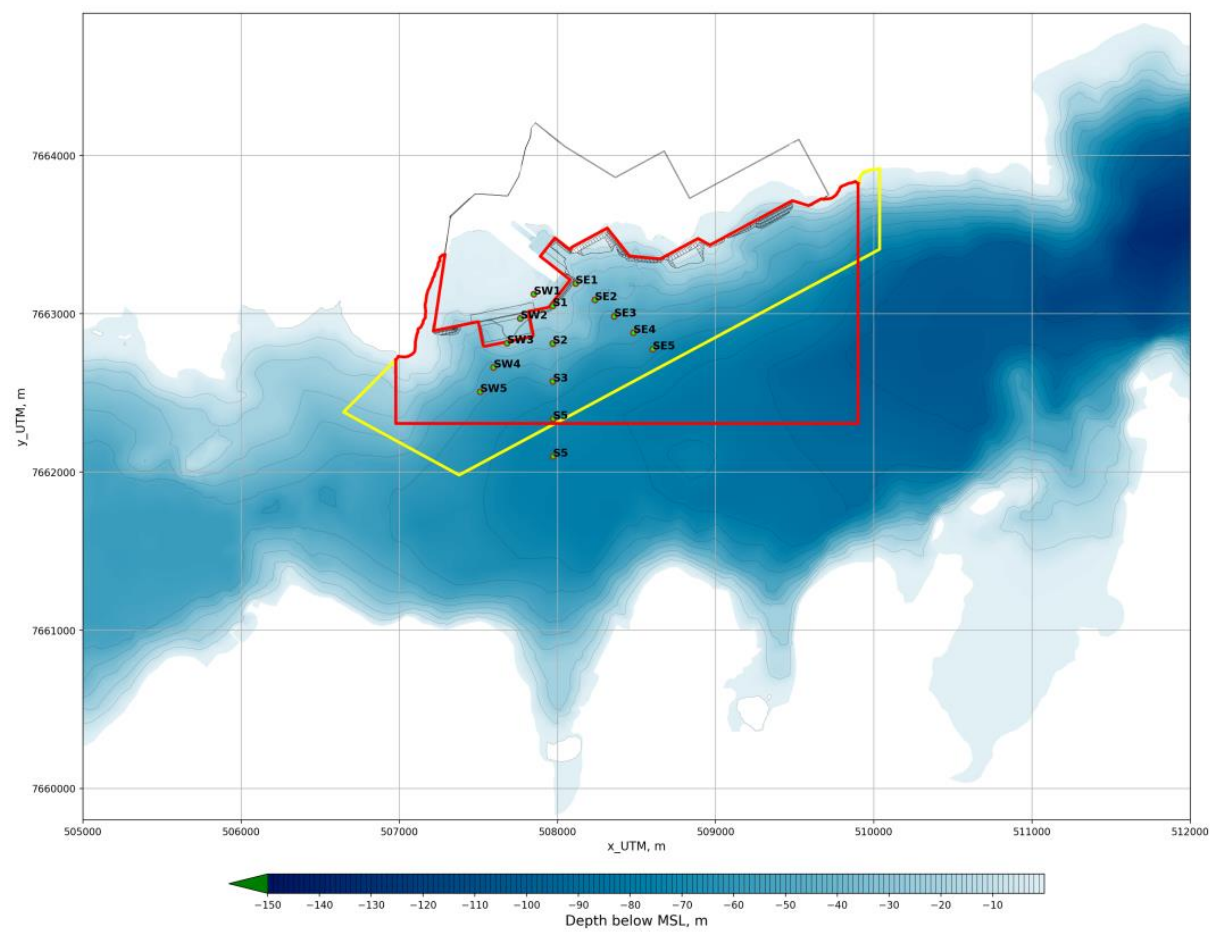

Fig.2.Bathymetry of the middle knee of the Kola Bay in the area of CCLMS, relative to the average sea level. Projection UTM 36, EPSG: 32636. Black color shows the scheme of hydraulic structures of the object; yellow-the boundary of the computational domain of the ARTEMIS model for SE waves, red-the boundary of the computational domain for waves E direction. The control points of the SWAN model results are also shown.

The figure also shows the boundaries of the calculated areas of the ARTEMIS model for the waves E and SE directions. And also-the position of 15 control points SW, 1-5, S, 1-5, SE, 1-5, for which, according to the results of the SWAN model, the elements of waves of different repeatability are calculated by the statistical methods.

The parameters of the waves at the point SE5 used directly for model initialization ARTEMIS, for waves of $E$ and SE directions.

Directionsrose the excitement of extreme storms, based on the results of model SWAN simulation in the point SE5 shown in Fig. 3. Waves of E direction have an average azimuth of $75^{\circ}, \mathrm{SE}-135^{\circ}$.

The calculation grid of the ARTEMIS model must be constructed taking into account the conditions of the numerical scheme of the model. For a detailed computational grid, it is necessary that the wavelength has at least 7 grid nodes at the wavelength. For a rough computational grid, a less rigid condition of 4-5 knots per wavelength is sufficient.

All waves of local dispersal are rather short. The period of $5 \%$ waves of $E$ direction is $3.74 \mathrm{~s}$, the period of $5 \% \mathrm{SE}$ waves is $2.79 \mathrm{~s}$, these corresponds to the wavelengths of $22 \mathrm{~m}$ and $12 \mathrm{~m}$, respectively.

The distribution of the wavelength in the region corresponding to the monochromatic wave with a period of 3 seconds (wavelength is about $14 \mathrm{~m}$ ) was taken as a basis for constructing a grid for the waves of Edirection. Accordingly, the grid cell size, by the ratio $\lambda / 7$, varies in the range from $1 \mathrm{~m}$ in shallow water to $2 \mathrm{~m}$ at the maximal water depth. The dimensions of the resulting grid: 894,654 node and 178,3447 elements.

For SE waves, the wavelength distribution corresponding to the monochromatic wave with a period of 2 seconds (wavelength $6.24 \mathrm{~m}$ ) was taken. But a less rigid condition $\lambda / 5$ 
was taken to construct the grid. What gives the mesh size on the deep water $\approx 1.25 \mathrm{~m}$. In shallow water, the cell size was limited by the size of $1 \mathrm{~m}$. the result is a mesh size 1748873 node and 3489155 elements.
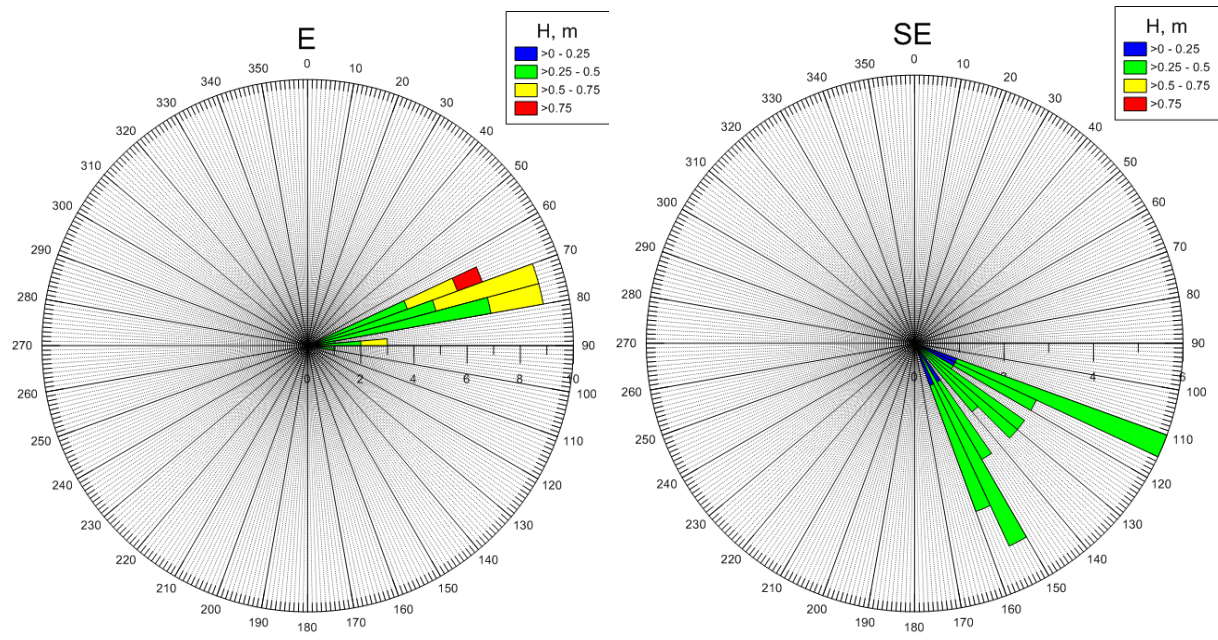

Fig.3.Rose of directions of the disturbances for extreme storms $E$ and SE quadrant-bearing, remodelirovania model SWAN point SE5. The color shows the maximum wave height at SE5 during a storm.

Bathymetry of computational grids is constructed taking into account the configuration of hydraulic structures of CCLMS. The final bathymetry relative to the average sea level is shown in Fig. 4 for the calculated grid of E waves and Fig. 5 for the computational grid of SE waves.

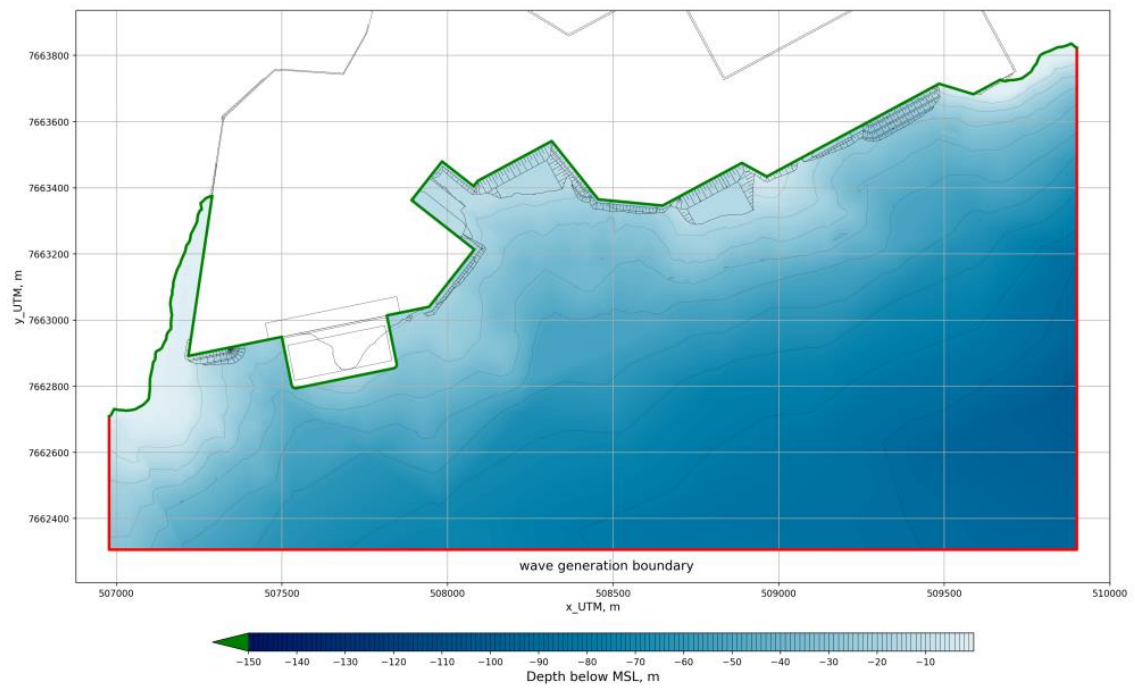

Fig.4.Bathymetry of the computational grid of the ARTEMIS model for modeling E waves relative to the mean sea level. Projection UTM 36, EPSG: 32636. The wave-generating boundary of the computational domain is shown in red, and the reflecting boundary is shown in green. 


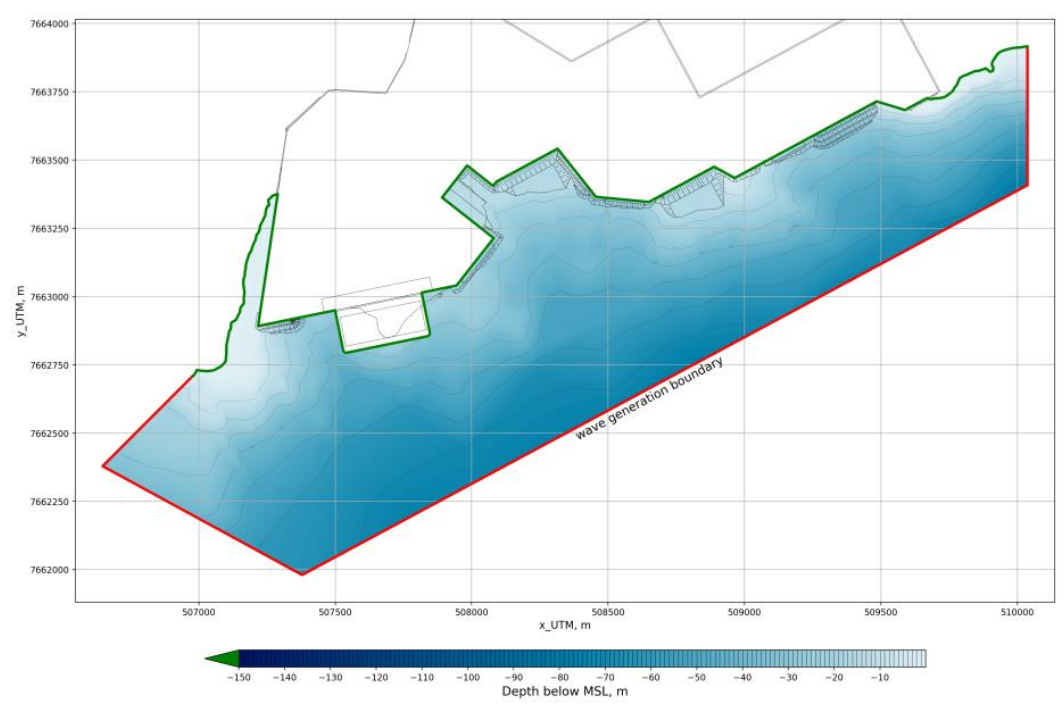

Fig.5.Bathymetry of the computational grid of the ARTEMIS model for modeling of SE waves relative to the mean sea level. Projection UTM 36, EPSG: 32636. The wave-generating boundary of the computational domain is shown in red, and the reflecting boundary is shown in green.

The figures also show the boundaries of the grids, wave-generating and reflecting. The reflection coefficient along the quays CCLMS was taken to be equal to the value of 0.3, along GBS - 0.6.

This technology of mathematical modeling in problems of marine hydraulic engineering and hydraulics was used in similar studies [5-9]. The authors took into account the experience gained in this study.

\section{Results and comparative analysis}

It was simulated $5 \%$ waves probability with the frequency of occurrence of 1 in 50 years for the three reference sea levels: average, minimum and maximum of $1 \%$ security.

The results of modeling the wave fields for E and SE direction are shown in Fig. 6 and 7. Figures 8 and 9 also show the values of wave heights at the control points along the GBS, as well as the maximal wave height at the GBS.

As seen in Fig.6,8, the E wave direction is suitable to the East side of the GBS at a small angle, so that the wave front is almost parallel to the GBS side. Here the wave reflected from the GBS is superimposed with the incident wave and the highest wave heights are observed near the GBS. On the South side of the GBS wave heights are noticeably lower and decrease in the direction from East to West.

The Western side of the GBS is in the shadow zone of E waves. Wave heights are very small: up to $0.1 \mathrm{~m}$.

The waves of the SE direction of the open South and East side of the GBS are shown in Fig.7, 9.

On the South side of the GBS, the reflected waves are superimposed with the incident waves, so that the wave field changes slowly along the side. The wave field on the East side of the GBS is inhomogeneous. Reflected from the GBS and berth №5 SE waves form a standing wave in the corner between the GBS and the berth, in the considered monochromatic case. Most likely, in the case of wind waves with some spectrum, there will 
be a wave crush. The Western side of the GBS is in the shadow zone of SE waves. Despite more than for $\mathrm{E}$ waves, diffraction, penetration, height of the waves here are small.

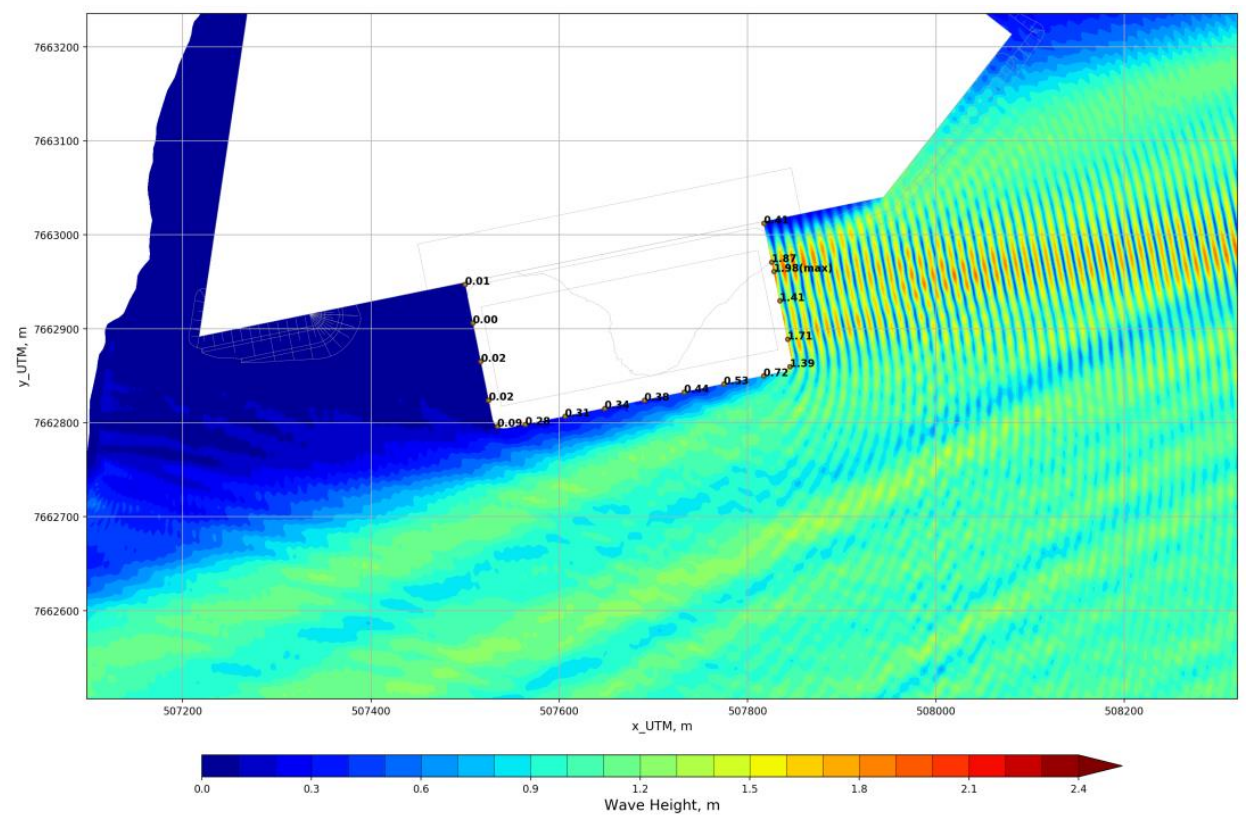

Fig.6.Wave heights E direction repeatability 1 every 50 years $5 \%$ th security in the waters of the CSMS near the OGT, for the average annual reference sea level.

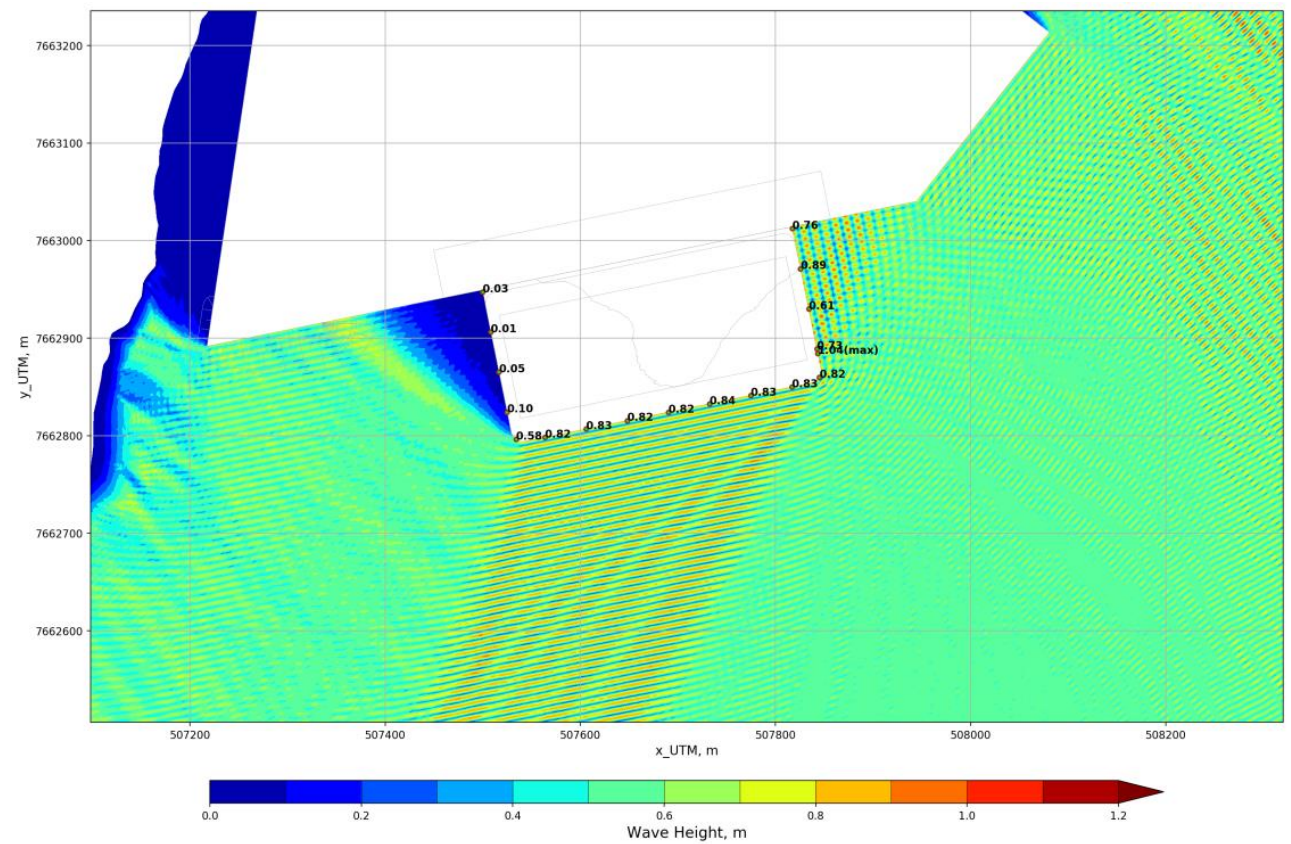

Fig.7.Wave heights SE direction repeatability 1 every 50 years 5\% th security in the waters of the CSMS near the OGT, for the average annual reference sea level. 


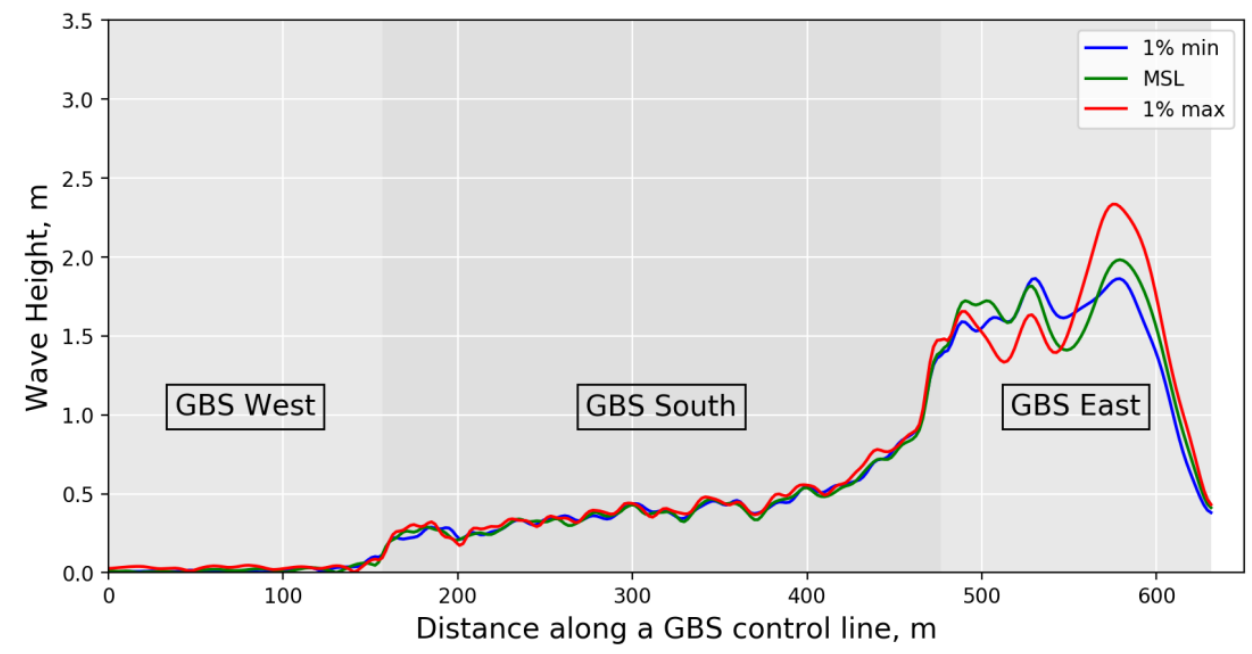

Fig.8.The distribution of wave heights along the GBS from West to East for the E wave direction frequency of occurrence of 1 in 50 years $5 \%$ accordance for sampling sea levels: average, minimum and maximum of $1 \%$ accordance.

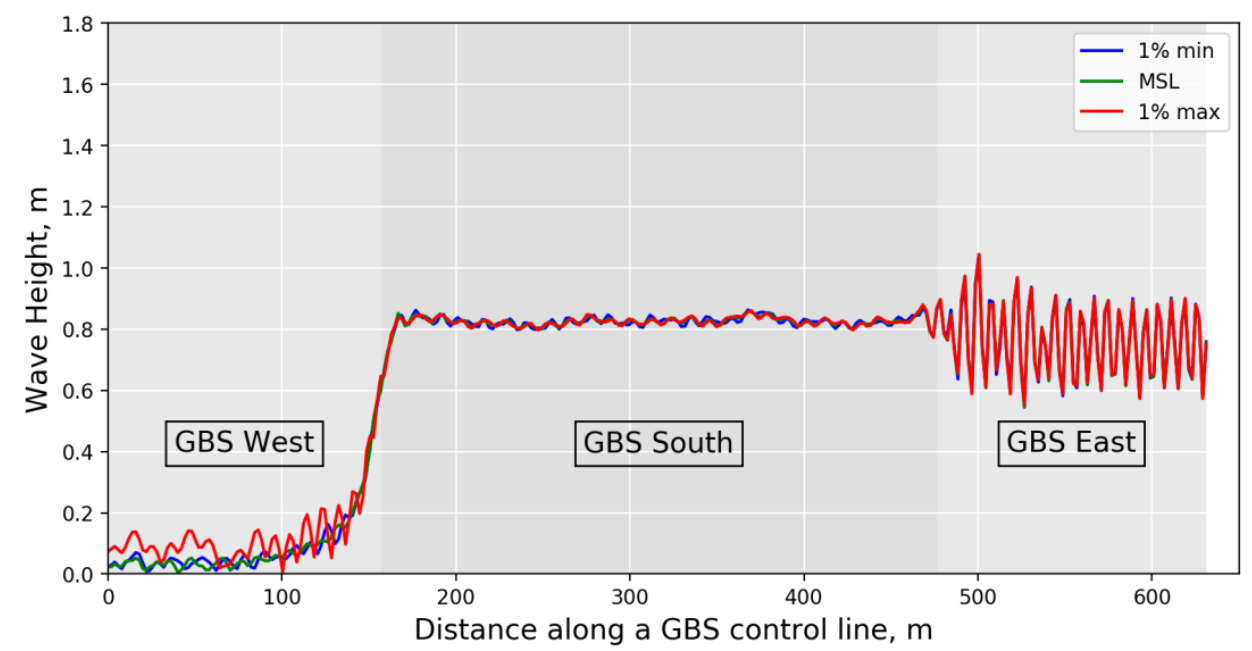

Fig.9.The distribution of wave heights along the GBS from West to East for the SE wave direction frequency of occurrence of 1 in 50 years 5\% probability for sampling sea levels: average, minimum and maximum of $1 \%$ accordance.

\section{Conclusions}

Based on the simulation results, we can conclude the following:

-wave heights on the West side of the GBS are similar for both directions and do not exceed $0.2 \mathrm{~m}$;

- wave heights on the South side of the GBS reach $1.05 \mathrm{~m}$ for SE waves;

- the height of the waves on the Eastern side of the GBS reaches values of $2.4 \mathrm{~m}$ for waves E directions;

- for all three reporting levels of the wave field, similar to the maximum height of waves close to a GBS observed at the maximal level of the sea. 


\section{References}

1. Holthuijsen L. H. Waves in oceanic and coastal waters. Cambridge University Press, (2007)

2. SWAN team. Swan cycle III version 41.10AB, Scientific and Technical documentation. Delft University of Technology, Faculty of Civil Engineering and Geosciences.(2017)

3. Aelbrecht DARTEMIS 3.0: A finite element model for predicting wave agitation in coastal areas and harbours including dissipation, WIT Transactions on The Built Environment, (1997)

4. Hervouet J M TELEMAC, a hydroinformatic system. La Houille Blanche, pp.21-28. (1999)

5. Kantardgi I., Zheleznyak M., Laboratornye i chislennye issledovaniya voln v akvatorii porta, Inzhenerno-stroitel'nyi jornal, (6), pp. 49-59, (2016) (In Russian)

6. Kantardgi I., Zheleznyak M., Demchenko R., Dykyi P., Kivva S., Kolomiets P., Sorokin M. Modelling of nonlinear hydrodynamics of the coastal areas of the Black Sea by the chain of the proprietary and open source models, Proceedings of EGU. Vienna, pp. 113-119, (2014)

7. Kantardgi I., Mordvincev K., Chislennoe i fhizicheskoe modelirovanie v MGSU morskih portovyh gidrotehnicheskih sooryzhenii, Nayka i bezopasnost', 32 (15), pp. 216, (2015) (In Russian)

8. Kantardgi I., ZheleznyakM., ShahinV., Matematicheskoe modelirovanie beregovyh processov Imeretinskoi nizmennosti dlya obosnovaniya beregozachitnyh meropriytii, Gidrotehnicheskoe stroitelstvo, 10, pp. 22-29, (2011) (In Russian)

9. Kantarzhi I., Anshakov A., The impact of approach channels on the waves in the port, IOP Conf. Ser.: Mater. Sci. Eng. 365(2018) 